\title{
Integrating Desktop Factory into Manufacturing Cloud: A Conceptual Model
}

\author{
L.J. Yao \\ School of Electronic Information \\ Shandong Institute of Commerce and Technology, \\ China
}

\author{
Y.S. Kong, X.J. Cheng, L. Ren \\ School of Automation Science and Electrical Engineering \\ Beihang University \\ China
}

\author{
Y.L. Wang \\ China Academy of Launch Vehicle Technology \\ China
}

\begin{abstract}
The desktop factories are playing increasingly significant roles in supporting on-demand manufacturing of customized products. However, most of the current desktop factories are running like isolated islands, making it difficult to integrate them into process lines to meet individualized needs. Cloud manufacturing is a smart networked manufacturing model as well as an integrated technology that enables service-oriented personalized manufacturing. This paper presents a conceptual model integrating desktop factories into manufacturing cloud. A desktop factory is regarded as a cloud terminal and the functional interfaces are mapped into standardized and configurable service modules. The proposed model of cloud-based desktop factories can provide a promising approach to aggregating microfactories into a cyber-physical virtual manufacturing society in the future.
\end{abstract}

Keywords-cloud computing; cloud manufacturing; desktop manufacturing; service-oriented manufacturing; desktop factory

\section{INTRODUCTION}

The desktop factories are playing increasingly significant roles in supporting sustainable manufacturing as well as ondemand manufacturing of customized and personalized products [1]. From a perspective of a product lifecycle, each desktop factory can be regarded as a process module which has a special capability. However, most of the current desktop factories are running like isolated islands [2], which makes it difficult to integrate the micro factories into high-level manufacturing lines flexibly to meet individualized requirements in real applications.

Recently, the convergence of advanced information technologies such as Cloud Computing [3], Internet of Things (IoT), and Cyber Physical System (CPS) [4] have transformed manufacturing paradigm as well as supporting technologies, which also provides a promising approach to integrating desktop factories into a IT-based smart factory networks. Cloud manufacturing [5-11] is proposed as a smart networked manufacturing model as well as an integrated technology that enables service-oriented, knowledge-based, highly collaborative and flexible manufacturing. In cloud manufacturing, the distributed manufacturing resources and capabilities are virtualized into a shared pool where users can acquire personalized services spanning a product lifecycle through the cloud networks.

In this paper we introduce cloud manufacturing into the desktop factories, and present a conceptual model integrating micro factories into manufacturing cloud. A desktop factory can be regarded as a cloud terminal, and the functional interfaces are mapped into standardized and configurable service modules. We present the basic operating model of cloud-based desktop factory and discuss the system model.

\section{THE CONCEPT OF CLOUD MANUFACTURING}

Cloud manufacturing is inspired by the concept of cloud computing. It is also based on the development of the technologies such as networked manufacturing, serviceoriented manufacturing, and virtual enterprise. Cloud manufacturing aims to interconnect distributed manufacturing resources such as machine cells and production lines by utilizing the Internet of Things technology and connect them with the Internet [5]. A cloud platform is responsible for management of the distributed resources in a centralized manner. In the cloud platform, the physical manufacturing resources are virtualized and aggregated into a virtual resource pool in which the virtual resources can be selected and customized according to personalized requirements.

Cloud manufacturing supports transforming manufacturing paradigm from production-oriented manufacturing to serviceoriented manufacturing. In cloud manufacturing, the functionalities involving the activities in a product life-cycle such as collaborative design, simulation, production, and assembling are all implemented in the form of services [6]. Hence, the Internet-based business models that can take advantage of collective intelligence, such as crowdsourcing, become possible and can be a frequently used business model in cloud manufacturing. 


\section{A CONCEPTUAL MODEL FOR CLOUD-BASED DESKTOP FACTORY}

\section{A. Basic Operating Model for Cloud-Based Desktop Factory}

Figure 1 depicts the basic operating model for cloud-based desktop factory. There are three kinds of actor roles participating the operation, i.e., cloud service provider, cloud operator, and cloud service factory. A cloud service provider can connect desktop factories such as 3D printers as cloud terminals to a cloud manufacturing platform. Via the cloud platform, a cloud service provider can offer manufacturing services such as 3D printing to the service consumers that have personalized manufacturing requirements.

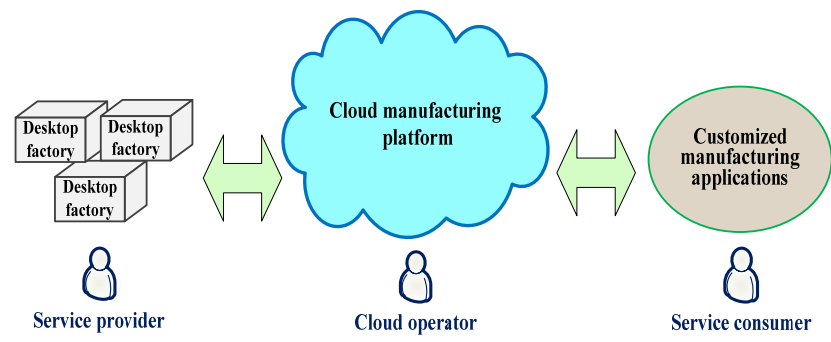

FIGURE I. BASIC OPERATING MODEL FOR CLOUD-BASED DESKTOP FACTORY.

The cloud manufacturing platform is responsible for centralized management of the desktop factories provided by the cloud service providers. According to the individualized needs of cloud service consumers, the cloud manufacturing platform can find suitable desktop factories that can undertake the demanded tasks. In addition, if a single desktop factory cannot fulfill the needs, the cloud manufacturing platform can aggregate a virtual manufacturing line relying on cloud service composition technologies to meet the needs.

From the perspective of benefit, the service consumers can acquire competitive manufacturing services with low cost and high quality because the cloud manufacturing platform can aggregate a large number of desktop factories. The utilization of the desktop factories of the service providers can be improved, and the service providers may earn the service fee according to specific business transaction rules.

\section{B. Cloud-Based Factory System Model}

Fig. 2 shows the cloud-based factory system model which consists of six layers, desktop factory interface layer, cloud access layer, virtual factory components layer, manufacturing service layer, user interface layer, and application layer.

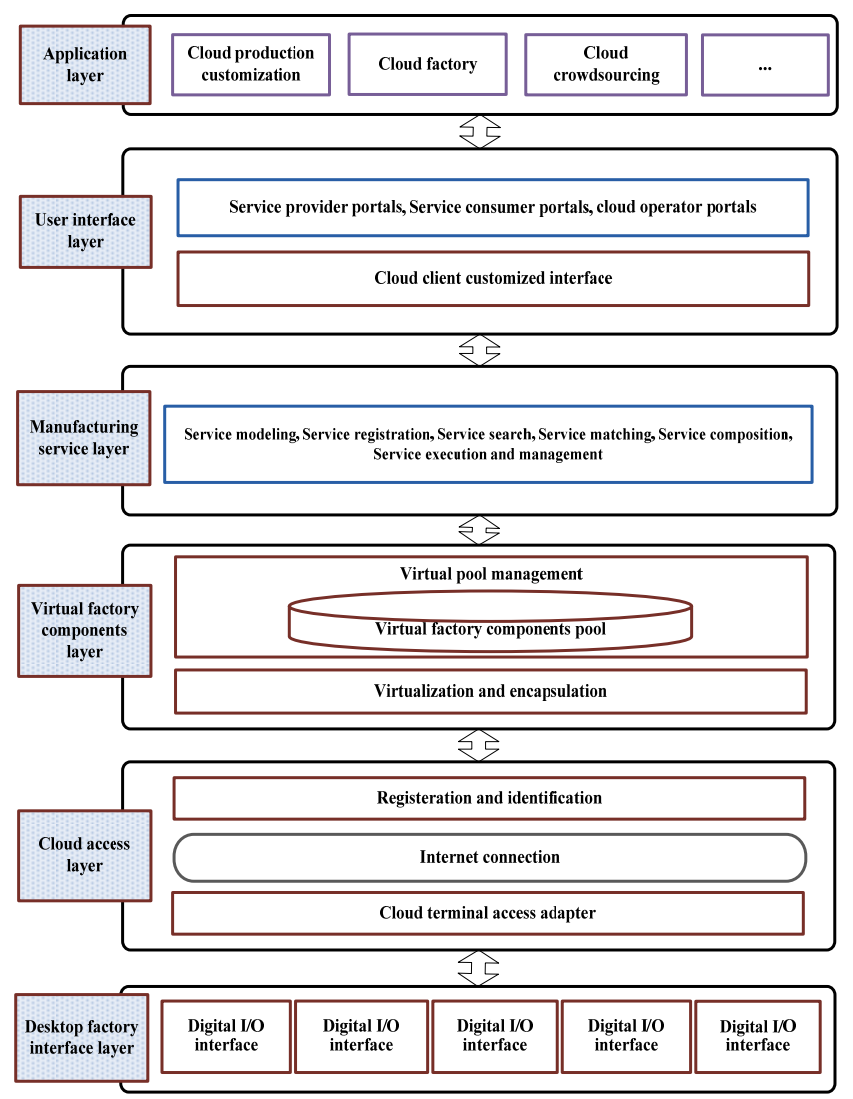

FIGURE II. CLOUD-BASED FACTORY SYSTEM MODEL.

Desktop factory interface layer

Digitalization plays a fundamental role in integrating a desktop factory into a cloud manufacturing platform. In order to be used over the Internet, a desktop factory need provide digital interfaces allowing information input and output. For those desktop factories without digital interfaces, the cloud service provider can publish them by registering the specific capabilities in the cloud manufacturing platform.

\section{Cloud access layer}

The cloud terminal access adapter is used to adapt to a variety of digital interfaces of desktop factories. Through the interfaces, the desktop factories will be connected to the Internet. As a cloud terminal, each desktop factory need register its basic information in the cloud manufacturing platform, and the platform will generate a unique identification for it.

\section{Virtual factory components layer}

In this layer, the physical desktop factories are virtualized and encapsulated into virtual manufacturing components. The virtualization process is based on model mappings. A multifunctional desktop factory can be mapped to multiple virtual factories and each provides a single function. Multiple desktop factories can be combined and build a virtual production line. The profiles for the virtual factories are stored 
and managed in the virtual factory components pool in this layer.

\section{Manufacturing service layer}

This layer is the main functional component of a cloudbased factory system. The Ontology technologies are used for modeling the semantics of the desktop factories, such as the formal models of domain-related concepts and logic, enabling intelligent understanding and management by cloud manufacturing platform. Manufacturing services are registered in the cloud manufacturing platform and then published for consumers' searching. Usually, service searching is based on semantic searching algorithms that can find more underlying suitable services. The cloud manufacturing platform is responsible for performing service matching between supply and demand. Service composition component is used to virtual components aggregation. As the composite service is running, this layer is responsible for scheduling and coordinating the cooperative desktop factories over networks. This layer also supports service billing and service evaluation.

\section{User interface layer and application layer}

The user interface layer mainly provides users the operation interfaces. The three types of users can customize their personalized interfaces to support daily work. The main applications involve cloud 3D printer, cloud factory, and cloud crowdsourcing.

\section{CONCLUSION}

This paper integrates small desktop factory with big manufacturing cloud and present a conceptual model. The basic operating model of cloud-based desktop factory and the system model are discussed. The proposed model of cloudbased desktop factories not only introduces a new business model for personal factories, but provides a promising approach to aggregating microfactories into a cyber-physical virtual manufacturing society in the future.

Future works include implementation of 3D printer integration with cloud manufacturing platform such as MfgCloud [5].

\section{ACKNOWLEDGEMENT}

The research is supported by the National High-Tech Research and Development Plan of China under Grant No. 2013AA041302, and the Fundamental Research Funds for the Central Universities in China.

\section{REFERENCES}

[1] Williams, A., Product-service systems in the automotive industry: the ca se of micro-factory retailing. Journal of Cleaner Production, 14(2), pp. 1 72-184, 2006.

[2] Siltala, N., Heikkila, R., Vuola, A. \& Tuokko, R., Architectures and inter faces for a micro factory concept. IFIP Advances in Information and Co mmunication Technology, 315(1), pp. 293-300, 2010.

[3] Buyya, R., Yeo, C. S., Venugopal, S., Broberg, J. \& Brandic, I., Cloud c omputing and emerging IT platforms: Vision, hype, and reality for delive ring computing as the 5th utility. Future Generation Computer Systems, 25(1), pp. 599-616, 2009.

[4] Wolf, W., Cyber physical systems. Computer, 42(3), pp. 88-89, 2009.

[5] Ren, L., Zhang, L., Tao, F., Zhao, C., Chai, X. \& Zhao, X., Cloud manuf acturing: From concept to practice. Enterprise Information Systems, 9(2), pp. 186-209, 2015.

[6] Ren, L., Zhang, L., Wang, L., Tao, F. \& Chai, X., Cloud manufacturing: Key characteristics and applications. International Journal of Computer Integrated Manufacturing, Online published, DOI: 10.1080/0951192X.2 014.902105, 2014. http://www.tandfonline.com/doi/abs/10.1080/095119 2X.2014.902105.

[7] Xu, X., From cloud computing to cloud manufacturing. Robotics and Co mputer Integrated Manufacturing, 28(1), pp. 75-86, 2012.

[8] Li, B.H., Zhang, L., Ren, L. \& et al, Further discussion on cloud manufa cturing. Computer Integrated Manufacturing Systems CIMS, 17(3), pp. 4 49-457, 2011.

[9] Wu, D., Rosen, D.W., Wang, L., \& Schaefer, D., Cloud-Based Design an d Manufacturing: A New Paradigm in Digital Manufacturing and Design Innovation. Computer-Aided Design, 59(1), pp. 1-14, 2015.

[10] Ren, L., Zhang, L., Zhang, Y., Tao, F. \& Luo, Y., Resource virtualizatio $\mathrm{n}$ in cloud manufacturing. Computer Integrated Manufacturing Systems CIMS, 17(3), pp. 511-518, 2011.

[11] Ren, L., Zhang, L., Tao, F., Zhang, X., Luo., Y. \& Zhang, Y., A method ology towards virtualisation-based high performance simulation platform supporting multidisciplinary design of complex products. Enterprise Inf ormation Systems, 6(3), pp. 267-290, 2012. 